\title{
Hydroxyethyl methyl cellulose as a modifier of gypsum properties
}

\author{
Patrycja Mróz ${ }^{1} \cdot$ Maria Mucha ${ }^{1}$
}

Received: 20 March 2017 / Accepted: 4 April 2018/Published online: 23 April 2018

(C) The Author(s) 2018

\begin{abstract}
The study is focused on the influence of a water-soluble polymer (in weight fraction up to $1.5 \%$ ), cellulose derivativeshydroxyethyl methyl cellulose, on gypsum properties. Gypsum setting involves two processes: gypsum hydration/crystallization and probably formation of a polymer film in material pores. The processes are studied by various methods such as setting time and mechanical measurements, scanning electron microscopy and differential scanning calorimetry. The additive acts as a retarder (an increase in setting time), and it modifies the morphology of calcium sulfate dihydrate crystals, leading to the change in mechanical properties-an increase in bending stress. The mechanism of gypsum crystal growth during hemihydrate hydration is predicted to be a nucleation control process (the Avrami equation is applied). The value of nucleation rate constant decreases with an increasing additive content.
\end{abstract}

Keywords Gypsum · Admixture $\cdot$ Hydroxyethyl methyl cellulose $\cdot$ Crystallization $\cdot$ Setting

\section{Introduction}

In recent years, interest in modification of building materials such as gypsum or cement by mixing with polymers has been observed. Polymers in small amounts may be applied as admixtures, dispersants or plasticizers. In all systems, the polymers act in different ways. In contrast to polymer dispersion, water-soluble polymers are dissolved in the mixing water on molecular scale and can form transparent films in gypsum pores [1-6].

Commercial gypsum boards are widely used in the building industry as facing materials for walls and ceilings due to their very good mechanical and thermal properties, as well as fire endurance [1]. The application of polymer admixtures to gypsum and cement is increasingly important. Currently used building materials, despite their advantages, may be mechanically more durable and resistant to moisture due to the addition of cellulose derivatives. These polymers are completely safe for health which makes them even more attractive [2].

Patrycja Mróz

mroz.patrycja@wp.pl

1 Faculty of Process and Environmental Engineering, Lodz University of Technology, Wólczańska 215, 90-924 Łódź, Poland
HEMC is one of the cellulose ethers which affects the properties of construction materials and also improves their workability [7-9]. In the case of cement and other building materials, cellulose ether can delay hydration. Pourchez predicts that methoxyl group has the biggest influence on hydration delay $[3,4]$.

Plank et al. [5, 6] and other researchers [8-10] showed that HEMC improved water retention of cement and gypsum. Already, a $0.3 \%$ dose of HEMC causes $97 \%$ of water retention capability. However, more than $1 \%$ of HEMC admixture can produce extremely viscous cement pastes. This effect is dependent on molecular weight of the polymer sample. An increase in filtrate viscosity may play a role in the working mechanism of HEMC [7]. Currently, the main applications of HEMC and other cellulose ethers are in wall plasters, floor screeds, waterproofing membranes, joint compounds for gypsum board paneling and cement tile adhesives [2, 11-14].

This work is focused mainly on the mechanical properties of gypsum plaster and hydration/crystallization of gypsum with various contents of HEMC. 


\section{Experimental}

\section{Materials}

The experimental material was hemihydrate sulfate $(\beta$ form) supplied (as gypsum) by Dolina Nidy (Poland). The material meets the requirements of standard PN-EN 13279-1:2009 [15]. It contains $90.98 \%$ calcium sulfate $\left(\mathrm{CaSO}_{4}\right)$ in gypsum. Other components include $\mathrm{CaCO}_{3}-$ $2.79 \%, \mathrm{SiO}_{2}-1.62 \%$, montmorillonite- $3.07 \%$, clays$0.79 \%$ and chlorite- $0.16 \%$. Distilled water was used to mix gypsum with admixtures. Hydroxyethyl methyl cellulose (HEMC) of viscosity equal to $3000 \mathrm{mPa}$ s was supplied by Atlas Company (Poland).

Figure 1 shows ether cellulose chemical structure with active groups to turn our account on possible interactions by hydrogen bonds with calcium sulfate dihydate.

\section{Preparation of samples}

The following samples were prepared to use in calorimetric, setting time and mechanical studies: gypsum without admixtures and gypsum with various HEMC contents $(0.25-1.5 \%)$. The water-to-gypsum ratio was equal to 0.6-0.74. Samples were prepared according to standard PN-86 B-04360 (Plasters. Test methods. Physical characteristic determination.) [16]. First, polymer admixtures in appropriate amounts were dissolved in distilled water at room temperature. Then, the composition with gypsum was vigorously mixed for $30 \mathrm{~s}$ using a mechanical stirrer to obtain homogeneous blends.

\section{Setting tests}

The rate of setting time was determined at room temperature using the Vicat's device (Master, Italy) with a stainless steel needle and ebonite ring. Contact surface of the needle was polished after every measurement. The study consists in a measure of free needle penetration into the gypsum paste every $30 \mathrm{~s}$. The study was conducted according to standard PN-86 B-04360 (Plasters. Test methods. Physical characteristic determination) [16].

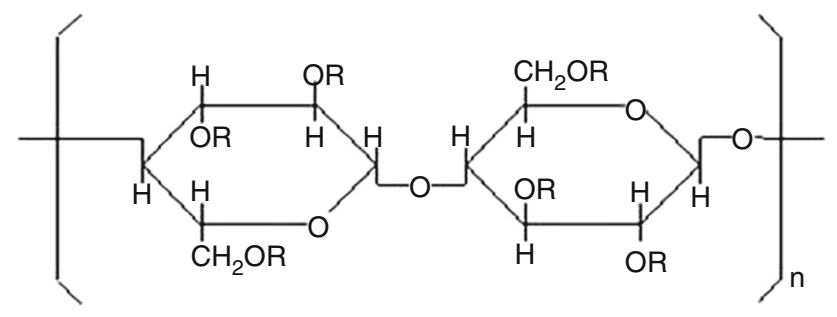

\section{Mechanical tests}

Mechanical bending tests for measure of flexural stress value $\sigma$ was carried out using Instron 3345 (Instron, USA). Samples were prepared for the bending test by spreading a hemihydrate paste on rubber molds attached to glass plates. Mold dimensions were $50 \mathrm{~mm} / 18 \mathrm{~mm} / 5 \mathrm{~mm}$. The tests were repeated 6 times for paste of the same composition. Before the experiment, the entire mold was smeared with oil. The applied samples were set for $48 \mathrm{~h}$ at room temperature. The study was conducted according to standard PN-86 B-04360 (Plasters. Test methods. Physical characteristic determination) [16].

\section{Calorimetric studies of the samples}

The hydration/crystallization process was followed by isothermal calorimetry. Milligrams of the prepared paste were placed in the calorimeter. The instrument was kept at controlled constant temperature of $30^{\circ} \mathrm{C}$. Heat flow was recorded up to $2 \mathrm{~h}$. After that time, it became very low. The cumulative heat proportional to the degree of hydration was calculated with reasonable accuracy. A Mettler calorimeter (DSC), model FP90, was applied.

\section{Microphotography}

A scanning electron microscope (SEM) model $1430 \mathrm{VP}$ (LEO Electron Microscopy Ltd, England) was applied to make microphotographs of gypsum fractures after the flexural mechanical tests. Variable vacuum mode of $50 \mathrm{~Pa}$, a BSE detector was used.

\section{Results and discussion}

Samples of gypsum plasters with initially various water-togypsum ratios which contained HEMC admixtures in weight fractions from 0.25 to $1.5 \%$ were prepared. Setting, mechanical and DSC tests were made. The results are shown in the following figures. The effect of HEMC admixture on the kinetics of gypsum hydration/crystallization process was discussed.

\section{Setting time}

Setting of material is a transition period during which the physical state of material changes from liquid to solid. This transformation occurs as a result of the development of hydrated products which cause rigid connections between hydrating grains. It is usually characterized by two points in the hydration process, namely initial and final setting

Fig. 1 HEMC structure 
time. The development of connected hydration product which reflects the transition of material state was measured by the penetration resistance technique.

Selected results of the Vicat needle test are shown in Figs. 2 and 3. The beginning of the setting period was estimated as the first inflection point on $h$ curve. The time of setting was measured as the time of the intersection of straight line on the curve. The time from the onset of the experiment to the beginning of the setting period is known as the induction period.

Figure 2 shows setting of the samples with water-togypsum ratio $x$ from 0.6 to 0.74 . In the case of higher water content (in initial gypsum mixture), the initiation of the setting process (initiation time $t_{\mathrm{i}}$ ) followed later than in the case of low water content. Gypsum setting time $t_{\mathrm{s}}$ also increased with increasing amounts of water. Excess water caused prolongation of the nucleation process and also adsorption/accumulation of ions or other molecular units at the interface due to lowering of the oversaturation degree.

Figure 3 illustrates the setting process of gypsum for samples with $w / g=0.66$ and various HEMC contents. In Fig. 3, for comparison, a sample without any admixtures with $w / g=0.66$ is also presented. The addition of a small amount of HEMC admixture (lower than 1\%) caused an insignificant prolongation of the setting and induction time. Results for the samples with $0.25,0.5$ and $0.75 \%$ are very similar. Compared to the samples with a smaller content of admixtures and those without any admixture, the addition of $1 \%$ prolongs the setting time. HEMC in the amount of $1.5 \%$ causes a significant (almost double) increase in the setting and induction time. The applied polymer prevents diffusion of water molecules and anions to the binder surface due to relatively rigid polymer molecule conformation in the water phase. No electrostatic interactions of polymer active groups with the binder surface of gypsum

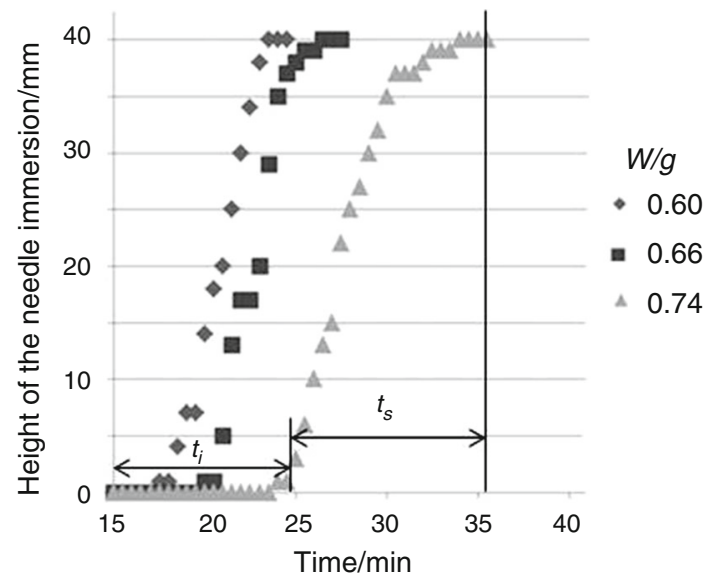

Fig. 2 Setting of gypsum obtained with various water-to-gypsum ratios $(w / g=0.6-0.74)$. Weight fraction of HEMC is equal to $0.5 \% . t_{\mathrm{s}}$ example of setting time measurements, $t_{\mathrm{i}}$ induction time of setting

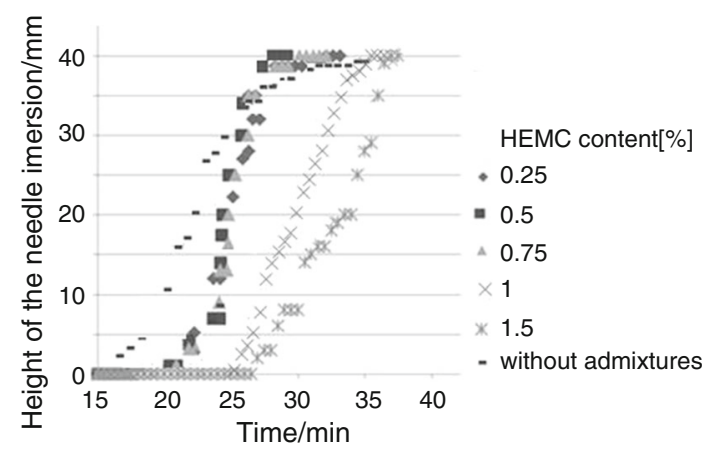

Fig. 3 Setting process of gypsum samples with $w / g=0.66$ for various HEMC contents $(0.25-1.5 \%)$ and for sample without admixtures

were predicted because it was found elsewhere that the gypsum zeta potential was close to zero [17].

Dependence of $t_{\mathrm{i}}$ and $t_{\mathrm{s}}$ on the $w / g$ ratio was presented in our previous paper [2].

\section{Mechanical tests}

The results of mechanical tests are shown in Figs. 4 and 5 . Figure 4 presents the dependence of bending stress $\sigma$ on HEMC content for water-to-gypsum ratio equal to 0.6-0.74. The bending stress increases with increasing HEMC content for chosen $w / g$. The higher values of $\sigma$ are received for a smaller water-to-gypsum ratio.

Figure 5 presents bending stress $\sigma$ versus water-togypsum ratio $w / g$. In both cases (samples without admixture and with $1 \%$ HEMC), the bending stress $\sigma$ decreases with increasing water content. It results from a change in the sample morphological structure and increasing pore content. Greater HEMC content causes the growth of overlapping crystals which leads to significantly increasing bending stress of the sample.

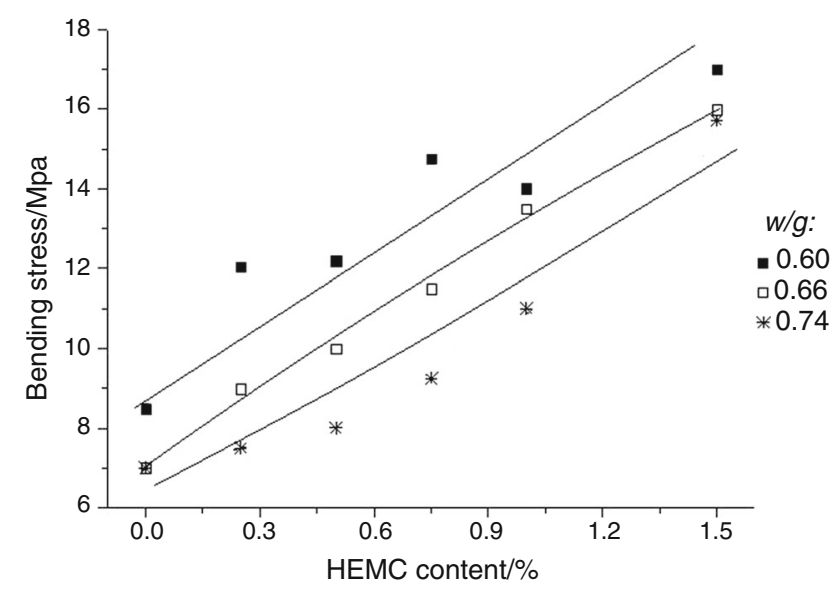

Fig. 4 Bending stress $\sigma$ versus HEMC content for various $w / g$ ratios. Error is equal to $1 \mathrm{MPa}$ 


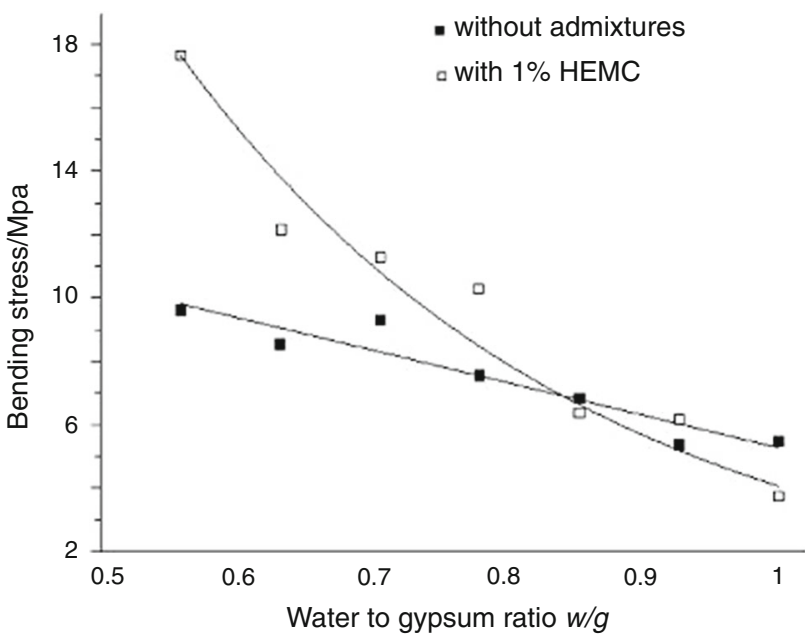

Fig. 5 Bending stress $\sigma$ versus water-to-gypsum ratio, $w / g$

\section{Hydration/crystallization process}

The hydration of calcium sulfate hemihydrate is an exothermic reaction

$\mathrm{CaSO}_{4} \cdot 0.5 \mathrm{H}_{2} \mathrm{O}+1.5 \mathrm{H}_{2} \mathrm{O} \rightarrow \mathrm{CaSO}_{4} \cdot 2 \mathrm{H}_{2} \mathrm{O}+Q$,

where $Q$, the amount of heat evolution, depends on a number of factors.

The reaction of gypsum with water [18-20] is divided into three main stages which involve a set of coupled chemical processes:

1. A nucleation period starts immediately after the hemihydrate powder sample is mixed with water solvent and dissolved. The dissolution involves detachment of molecular units from a solid surface in contact with water as well as diffusion and transport of solution components into volume paste. The solution becomes supersaturated with respect to $\mathrm{Ca}^{2+}$ and $\mathrm{SO}_{4}^{2-}$ ions, which leads to the precipitation of solid grains of calcium dihydrate due to the nucleation process.

2. An acceleration period in which a complex reaction between ions or solid complexes adsorbed on solid surfaces due to the crystallization/hydration process is observed.

3. A deceleration period of very slow reactions of adsorption and accumulation of ions or other molecular units at an interface. The late stage of hydration is thus controlled by the diffusion process.

The wide range of properties can be observed as hydration proceeds, including heat of hydration, porosity and setting time as well as phase volume fraction.
The rate of all the reactions can be changed by the presence of a polymer admixture. For example, the induction period can be prolonged with:

a. Reduced diffusion of water and calcium ions at gypsum surface because the adsorbed polymer (if so) hinders the process,

b. Formation of a complex between calcium ions and the polymer in the pore solution,

c. Change in the growth kinetics and morphology of hydrated phases caused by the dispersive action of the polymer.

Experimental observations have suggested that the formation of a cementitious hydrated product is a rate-controlling process at early stages [19]. Furthermore, this led to the development of hydration kinetics models based on nucleation and growth phenomena such as presented by Avrami et al. [21, 22].

Avrami [21, 22] and also Johnson and Mehl [23], as well as Kolmogorov [24], proposed a simple but widely used equation which is derived using the assumption within the transforming volume in changing liquid on crystal. Avrami power law is as follows:

$X(t)=1-\exp \left(-K t^{\mathrm{n}}\right)$,

where $X(t)$ is the volume fraction of crystalline phase that is transformed at time $t, K$ is the combined rate constant that involves the rates of growth and nucleation, and $n$ is a parameter dependent on the mechanism and dimensionality of growth.

Depending on crystal, growth $n$ can reach a value between 1 and 3 . If $n \approx 1$, the growth will have onedimensional (needle) character. In the case of $n \approx 2$, two dimensions and $n \approx 3$ isotropic growth (sphere) are observed [25, 26].

The volume of the transformed phase will increase with the simple power law (Avrami equation) at early stages of the process before adjacent regions of the growing product impinge. Thus, the overall growth rate in the system decreases with time.

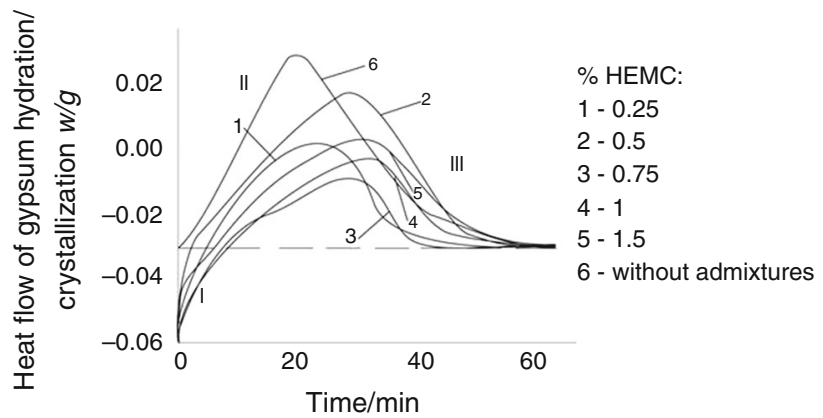

Fig. 6 Isothermal DSC curves: heat flow of gypsum hydration/ crystallization versus time for various HEMC contents, $w / g=0.66$ 
It is commonly assumed that hydration is the diffusion controlled by the rate at which the reactants can diffuse through the nanoporous layer of hydration product around

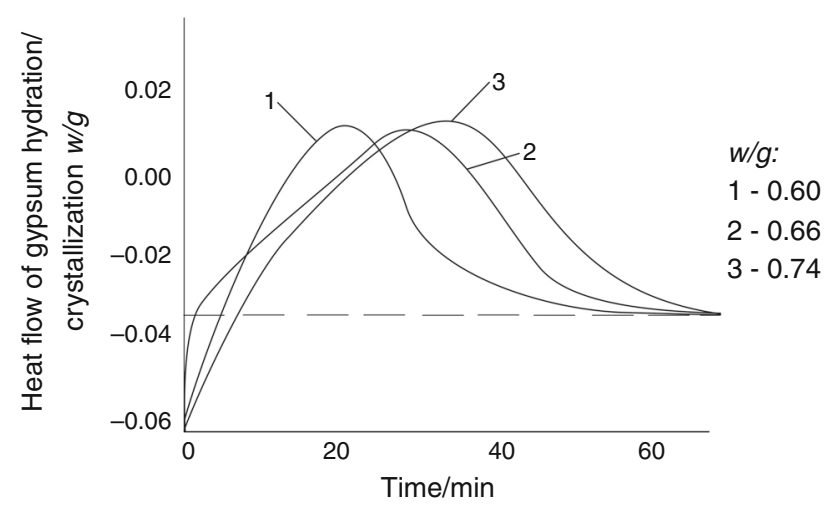

Fig. 7 Isothermal DSC curves: heat flow of gypsum hydration/ crystallization for various $w / g$ (for $0.5 \%$ HEMC content) the remaining unhydrated gypsum particles. The point in which the hydration process shifts away from nucleation and growth is not well established, but it is an important aspect of the hydration process.

The increasing use of mineral or polymer admixtures in cementitious materials leads to the question how the admixtures can affect hydration rate, especially at early stages.

The wide range of sample properties can be observed as hydration/crystallization proceeds, including heat of hydrated phase, volume fraction, chemical shrinkage, percolation of capillary porosity and setting time.

Hydration/crystallization of calcium hemihydrates, both pure and with admixtures, was conducted by DSC research. Figures 6 and 7 show curves of the process. Figure 6 presents curves obtained for samples with the water-togypsum ratio equal to 0.66 . Gypsum hydration occurs in the main three-stage processes, i.e., nucleation (I), acceleration (II) and deceleration (III). The hydration/
Fig. 8 a Curves from Fig. 6 transformed into Avrami plots-degree of hydration/ crystallization $X$ versus time t. b. $\log [-\ln (1-X)]$ versus $\log t$

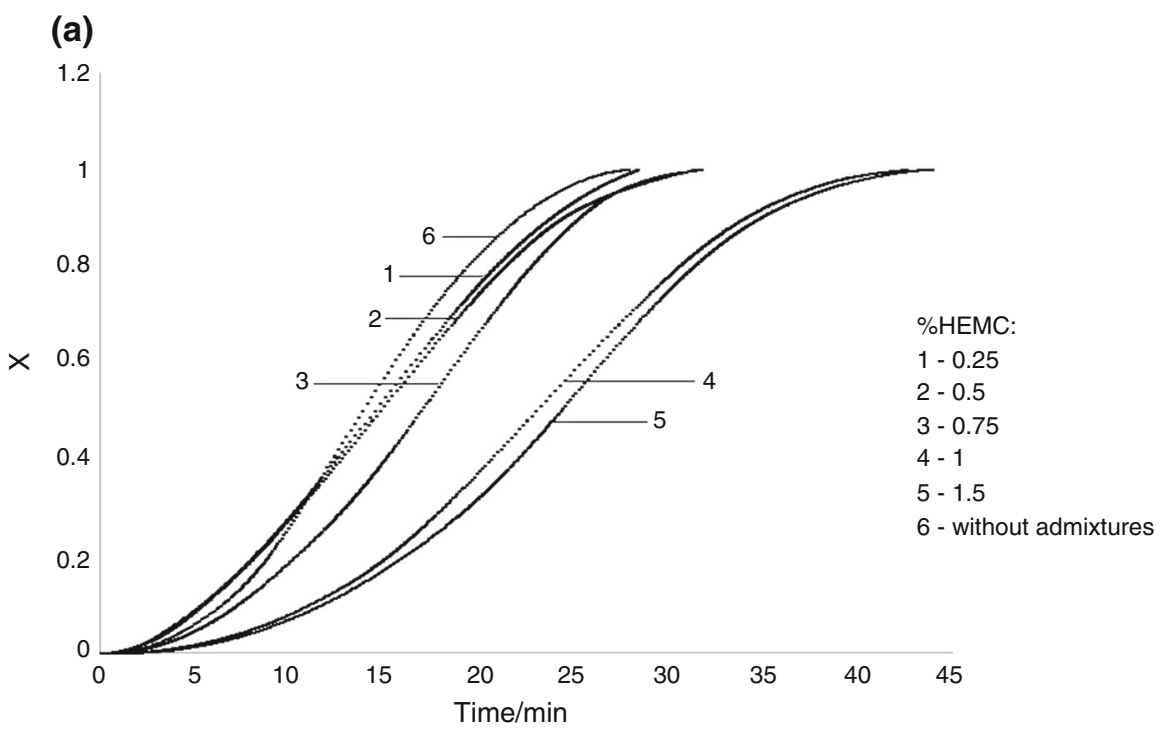

(b)

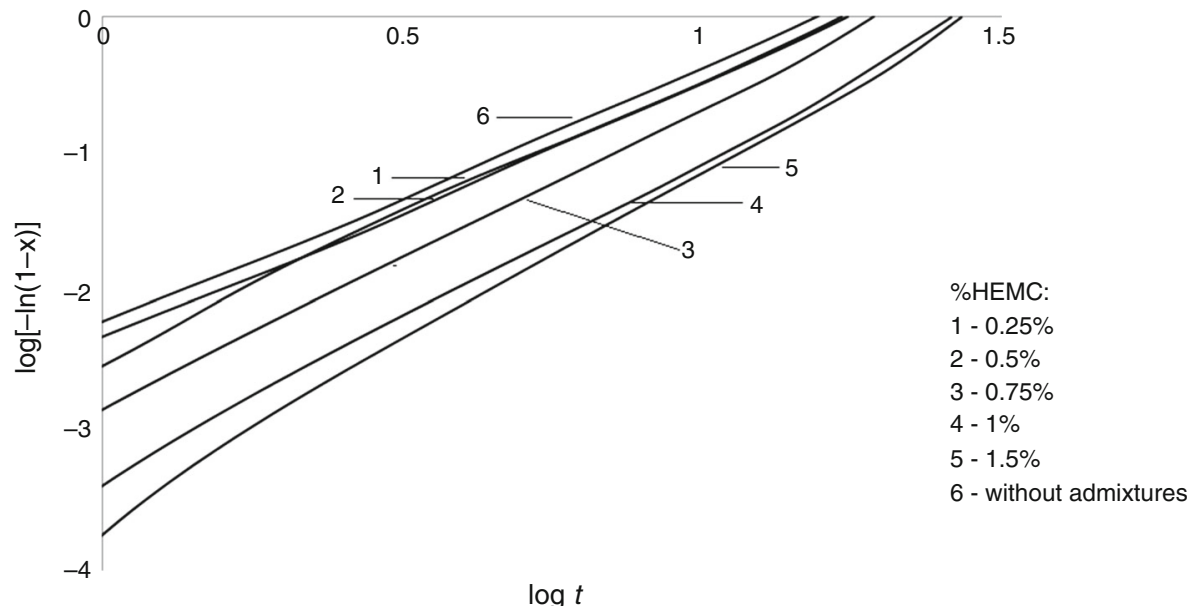

$\log t$ 
crystallization process occurs faster in the case of sample 6 (without admixtures). The increasing polymer content causes a delay of the hydration/crystallization process. Not only the induction period is extended, but also the rate of the following hydration reaction is slowed down. This is illustrated by lower values of maximum heat release and broader exothermal peaks in the calorimetric curves of the polymer-modified pastes.

Figure 7 shows samples with various water-to-gypsum ratios (0.60-0.74) and HEMC content equal to $0.5 \%$. With an increasing $w / g$ value, the hydration/crystallization process also delays. Both the presence of polymer in water solution and increasing $w / g$ ratio leading to the delay of gypsum hydration/crystallization result from the same prevention of nucleation process of gypsum species.

Figure 8a presents curves transformed in Fig. 6 to the plots of the degree of hydration/crystallization $X$ drawn versus time. Figure $8 \mathrm{~b}$ shows $\log [-\ln (1-X)]$ versus $\log$ $t$ (obtained according to Avrami equation).

The values of crystal growth rate constant $K$ (dependent on the nucleation rate) are determined from Fig. 8a, b and presented in Fig. 9 (parameter $n \approx 1.4$ ). An increasing polymer admixture content causes a decrease in the $K$ value. The results indicate that HEMC is an efficient agent disturbing the nucleation and crystallization of gypsum (lower $K$ value).

\section{SEM microphotographs}

The morphology of calcium sulfate dihydrate crystals depends on the formation conditions and the presence of additives [9]. SEM microphotography is helpful for observation of gypsum crystals. Figures 10 and 11 present microphotographs of bending fracture area of the samples with water-to-gypsum ratio equal to 0.6 (with the admixture in Fig. $11-0.5 \%$ of HEMC). The crystal habit is affected by the presence of polymer as may be seen in the SEM photographs. Crystals in the absence of admixtures are thin and elongated which is a result of their rapid

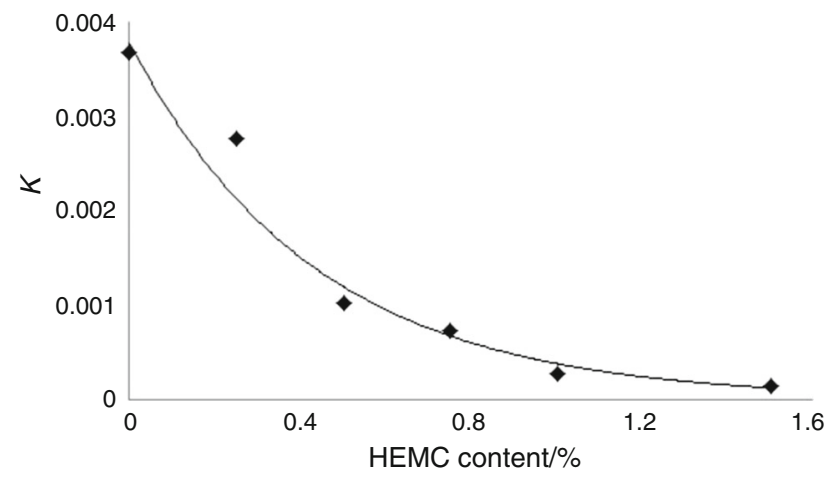

Fig. 9 Parameter $K$ versus HEMC content

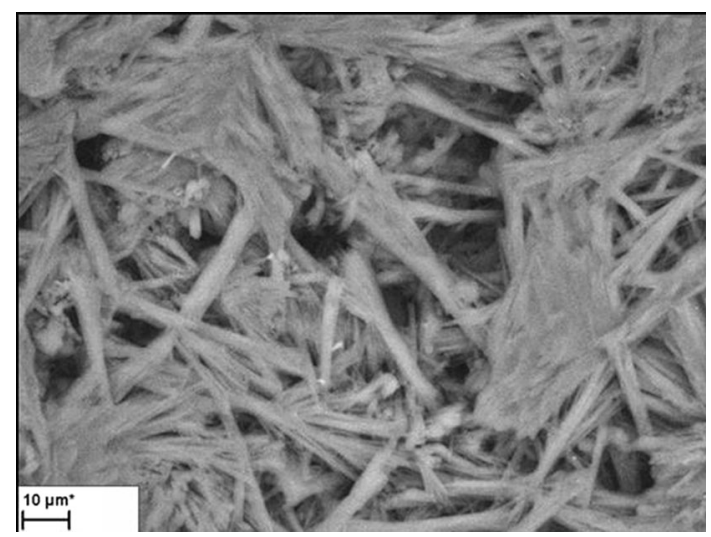

Fig. 10 Microphotograph of bending fracture area of the sample with $w / g=0.6$

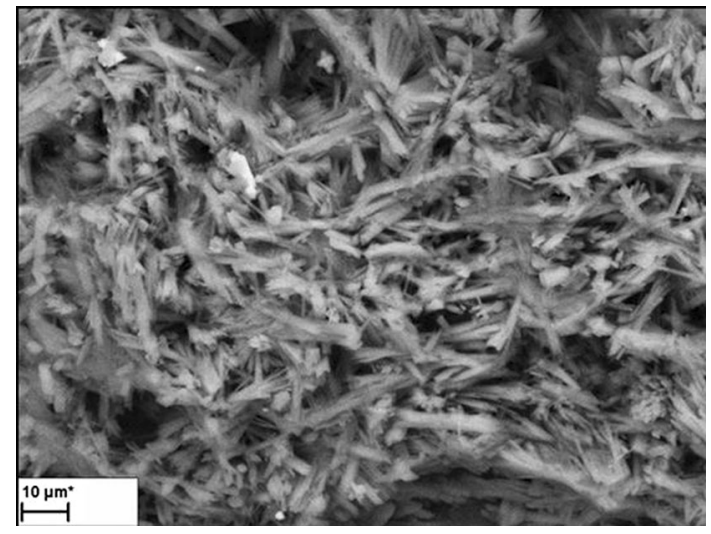

Fig. 11 Microphotograph of bending fracture area of the sample with $w / g=0.6$ containing $0.5 \%$ HEMC

growth. They are longer than in the case when HEMC is added. The presence of the polymer in the reacting solution enhances the agglomeration of crystals. A decrease in the total pore volume and increase in crystal overlapping lead to a more impact structure and higher mechanical strength.

Admixtures in the form of water-soluble polymers change the interaction between $\mathrm{Ca}^{2+}, \mathrm{SO}_{4}^{2-}$ and $\mathrm{OH}^{-}$ions forming hydrated crystals of gypsum. Polymers are not built into gypsum crystals but can form a separate phase (for example thin films in the pores).

\section{Conclusions}

Results of the above-presented studies on gypsum properties and hydration/crystallization process lead to the following conclusions:

1. Higher supersaturation of gypsum solution (low $w / g$ ratio) means a quicker growth of gypsum crystals and 
shorter setting time (Fig. 2). The increasing $w / g$ leads to the decrease in system saturation (Fig. 2).

2. Retardation of the setting and hydration/crystallization process due to the presence of water-soluble HEMC is observed (Fig. 3).

3. The rise of bending stress with increasing HEMC content (Fig. 4) and $w / g$ ratio (Fig. 5) is due to changing morphological structure of the sample. The decrease in pore volume and increase in crystal overlapping cause a more compact structure and higher strength (bending stress) of the samples.

4. Diffusion-controlled crystal growth is disturbed by the presence of polymer chains in the solution system-a decreased nucleation rate (Fig. 9).

5. Additives to gypsum in the form of water-soluble polymers change the interaction between $\mathrm{Ca}^{2+}$ and $\mathrm{SO}_{4}{ }^{2-}$ ions forming hydrated crystals of gypsum. They are not built-in crystals, but form a separate phase (Figs. 10 and 11).

Acknowledgements The research was funded by the National Science Centre (OPUS 6) under Project No. UMO-2013/11/B/ST8/04308.

Open Access This article is distributed under the terms of the Creative Commons Attribution 4.0 International License (http://creative commons.org/licenses/by/4.0/), which permits unrestricted use, distribution, and reproduction in any medium, provided you give appropriate credit to the original author(s) and the source, provide a link to the Creative Commons license, and indicate if changes were made.

\section{References}

1. Kontogeorgos DA, Founti MA. Gypsum board reaction kinetics at elevated temperatures. Thermochim Acta. 2012;529:6-13.

2. Mróz P, Mucha M. Hydration kinetics of calcium sulphate hemihydrate modified by water-soluble polymers. Int J Eng Res Sci. 2017;3(6):5-13.

3. Pourchez J. HEC influence on cement hydration measured by conductometry. Cem Concr Res. 2006;36:1777-80.

4. Pourchez J, et al. HPMC and HEMC influence on cement hydration. Cem Concr Res. 2006;36:288-94.

5. Plank J, Kainz J, Bülichen D. Working mechanism of methyl hydroxyethyl cellulose (MHEC) as water retention agent. Cem Concr Res. 2012;42:953-9.

6. Bülichen D, Plank J. Water retention capacity and working mechanism of methyl hydroxypropyl cellulose (MHPC) in gypsum plaster-which impact has sulfate? Cem Concr Res. 2013;46:66-72.

7. Brumaud $\mathrm{C}$, et al. Cellulose ethers and water retention. Cem Concr Res. 2013;53:176-84.

8. Patural L, Marchal P, Govin A, et al. Cellulose ethers influence on water retention and consistency in cement-based mortars. Cem Concr Res. 2011;41(1):46-55.

9. Mucha M, Kocemba A. Water retention and setting in gypsum/ polymers composites. Przemysł Chem. 2016;95:1003-5.

10. Ciobanu C, Iluc S, Lazau I, et al. Some physico-mechanical properties of dry mortars containing cellulose ethers. Rom J Mater. 2011;41(1):30-41.

11. Pichniarczyk P, Niziurska M. Properties of ceramic tile adhesives modified by different viscosity hydroxypropyl methylcellulose. Constr Build Mater. 2015;77:227-32.

12. Garg M, Pundir A. Investigation of properties of fluorogypsumslag composite binders-hydration, strength and microstructure. Cem Concr Res. 2014;45:227-33.

13. Singh M, Garg M. Relationship between mechanical properties and porosity of water-resistant gypsum binder. Cem Concr Res. 1996;26:449.

14. Murtias C, Jolliff Y, Nait-Ali B, Roger J, Favotto C. A new composite based on gypsum matrix and mineral additives. Hydration process of the matrix and thermal properties at room temperature. Thermochim Acta. 2013;567:15-26.

15. Norm PN-EN 13279-1:2009.

16. Norm PN-86 B-04360 standard, Plasters. Test methods. Physical characteristic determination.

17. Plank J, Hirsch Ch. Impact of zeta potential of early hydration phases on superplasticizer adsorption. Cem Concr Res. 2007:37:537-42.

18. Singh NB, Middendorf B. Calcium sulphate hydration leading to gypsum crystallization. Prog Cryst Growth Charact Mater. 2007;53:57-77.

19. Lewry AJ, Williamson J. The setting of gypsum plaster part 1: the hydration of sulphate hemihydrate. $J$ Mater Sci. 1994;29:5279-84.

20. Guan B, Je Q, Zhang J, Lou W, Wu Z. Interaction between $\alpha$ calcium sulphate hemihydrate and superplasticizer from the point of adsorption characteristics, hydration and hardening process. Cem Concr Res. 2010;40:253-9.

21. Avrami M. Kinetics of phase change. J Chem Phys. 1939;7:1103-12.

22. Avrami M. Kinetics of phase change. J Chem Phys. 1940;7:1212-24.

23. Johnson WA, Mehl RF. Reaction kinetics in process of nucleation and growth. Trans Am Inst Min Metall Eng. 1939;135:416.

24. Kolmogorov AN. A statistical theory of the recrystallization of metals. Bull Russ Acad Sci Phys. 1937;1:255.

25. Ridi F, Dei L, Fratini E, Chen S-H, Baglioni P. Hydration kinetics of tri-calcium silicate in the presence of superplasticizers. J Phys Chem. 2003;107:1056-61.

26. Wunderlich B. Macromolecular physics, vol. 2. New York: Academic Press; 1976. 